\title{
Penggunaan Metode Observasi Partisipan untuk Mengidentifikasi Permasalahan Operasional Suroboyo Bus Rute Merr-ITS
}

\author{
Putri Dwitasari, Nurina Orta Darmawati, Naufan Noordyanto, Vonny Aulia Sittasya, Weldiyanti Zulraniyah, \\ Fathinah Dinda Raihanah, dan Aprilia Annisa Karim \\ Departemen Desain Komunikasi Visual, Fakultas Desain Kreatif dan Bisnis Digital, \\ Institut Teknologi Sepuluh Nopember, Surabaya, Indonesia \\ e-mail:dwitasariputri@gmail.com
}

\begin{abstract}
Abstrak-Penggunaan Suroboyo Bus sebagai Transportasi umum merupakan bentuk pelayanan untuk masyarakat di Surabaya, yang penggunaannya meningkat setiap tahun. Salah satu rute yang banyak diminati adalah Merr-ITS. Seiring dengan animo masyarakat, dibutuhkan peningkatan pelayanan serta efektivitas operasional untuk memenuhi kebutuhan Suroboyo Bus sebagai Transportasi Massal yang sesuai dengan standar operasioanal. Tujuan dari riset ini adalah mengidentifikasi permasalahan operasional pada Suroboyo Bus Rute Merr-ITS dengan menganalisa faktor muat, jumlah penumpang, waktu tunggu penumpang, kecepatan perjalanan, sebab keterlambatan, fasilitas, dan ketersediaan angkutan yang kemudian dapat diolah menjadi sebuah data untuk pengembangan Suroboyo Bus. Metode yang digunakan adalah observasi partisipan untuk menganalisa permasalahan operasional Suroboyo bus secara langsung. Hasil riset diharapkan dapat mengidentifikasi permasalahan yang ada pada Transportasi umum Suroboyo Bus sehingga dapat digunakan sebagai rujukan oleh Pemerintah Kota Surabaya untuk lebih meningkatkan efektivitas operasional serta peningkatan pelayanan Suroboyo bus kedepannya.
\end{abstract}

Kata Kunci - metode observasi partisipan, efektivitas operasional, Suroboyo Bus, rute Merr-ITS

Abstract-Use of Suroboyo Bus as public transportation is a form of service for people in Surabaya, whose use is increasing every year. One route that is in great demand is Merr-ITS. Along with the public interest, needed to improve services and operational effectiveness to meet the needs of Suroboyo Bus as Mass Transportation by operational standards. The purpose of this research is to identify operational problems on the Suroboyo Bus Merr-ITS Route by analyzing the load factor, the number of passengers, passenger waiting time, travel speed, due to delays, facilities, and transportation availability which can then be processed into data for the development of Suroboyo Bus. The method used is a participant observation to analyze Suroboyo bus operational problems directly. The results of the research are expected to identify the problems that exist in Suroboyo Bus Public Transportation so that it can be used as a reference by the Surabaya City Government to further improve operational effectiveness and improve Suroboyo bus services going forward.

Keywords - participant observation method, operational effectiveness, Suroboyo Bus, Merr-ITS route

\section{PENDAHULUAN}

Meningkatnya intensitas pengguna kendaraan pribadi, membuat kepadatan di jalanan Surabaya semakin tidak terkontrol. Sebagai salah satu kota dengan tingkat kemacetan yang tinggi, Surabaya memerlukan sebuah solusi transportasi massal sebagai alternatif pengganti kendaraan pribadi. Pemerintah Kota Surabaya terus berupaya menciptakan berbagai solusi agar warganya beralih dari transportasi pribadi ke sistem transportasi publik untuk mengurangi tingkat kemacetan di Surabaya. Namun, jika melihat kondisi transportasi publik, rute serta fasilitas dan pelayanan transportasi yang ada di Surabaya, masyarakat lebih memilih untuk menggunakan kendaraan pribadi dengan alasan efisiensi dan kenyamanan.
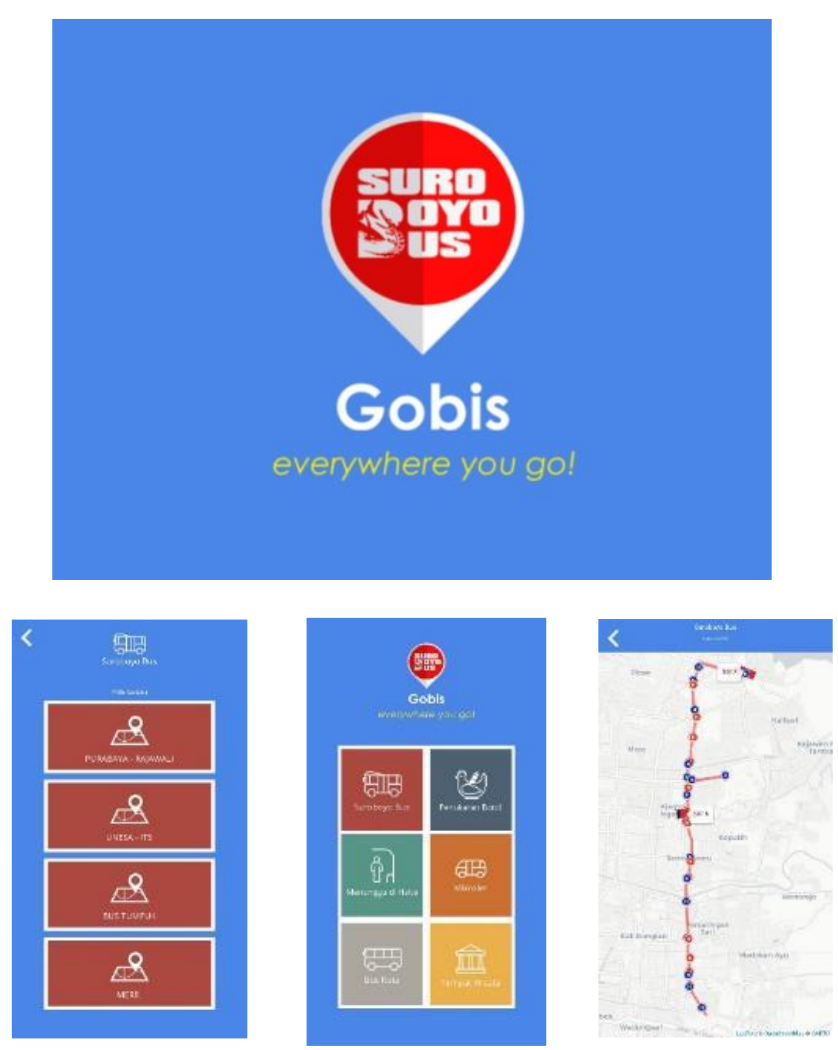

Gambar 1. Aplikasi GoBis Suroboyo Bus 
Putri Dwitasari, Nurina Orta Darmawati, Naufan Noordyanto, Vonny Aulia Sittasya, Weldiyanti Zulraniyah, Fathinah Dinda Raihanah, dan Aprilia Annisa Karim

Penggunaan Metode Observasi Partisipan untuk Mengidentifikasi Permasalahan Operasional Suroboyo Bus Rute Merr-ITS

Salah satu upaya pemerintah kota untuk mengurangi kemacetan adalah dengan mengeluarkan moda transportasi publik alternatif yakni Suroboyo Bus. Suroboyo Bus adalah salah satu kendaraan umum di Surabaya yang diresmikan oleh Bu Tri Rismaharini sejak Bulan April 2018. Suroboyo Bus berbeda dengan transportasi umum yang sebelumnya ada di Surabaya. Suroboyo Bus memiliki desain modern, dapat menggunakan aplikasi GoBis saat hendak mengaksesnya. Aplikasi GoBis dibuat untuk mempermudah penumpang, memberikan pengalaman baru bagi para penumpang, serta untuk menciptakan sistem yang lebih terintegrasi, seperti yang dapat dilihat pada Gambar 1. Selain itu, Suroboyo bus memiliki rute beragam, memiliki sistem yang terintegrasi dengan sistem pengaturan lalu lintas jalan. Lampu lalu lintas secara otomatis akan berubah menjadi hijau jika bus ini melintas dengan pusat kontrol yang berada di Terminal Bratang dan Joyoboyo [1]. Sistem pembayaran yang diberlakukan juga tidak menggunakan uang melainkan menggunakan sampah plastik berupa kemasan botol minuman. Hal tersebut yang menjadikannya salah satu daya tarik baru di Surabaya. Tujuan dari Suroboyo Bus adalah untuk menarik minat masyarakat Surabaya agar beralih ke penggunaan transportasi publik, serta mengurangi sampah plastik di Surabaya.

Sejalan dengan 2 tahun keberadaannya, Suroboyo bus telah dapat diterima oleh masyarakat sebagai alternatif transportasi untuk mobilitasnya. Penumpangnya semakin meningkat, hal Ini ditunjukkan dari jumlah penumpang bus yang mencapai 873.310 hingga Oktober 2019. Selain itu, Pemkot Surabaya juga meningkatkan layanan dengan tiga koridor, sehingga waktu tunggu atau headway lebih pendek [2]. Dengan rencana yang dikemukakan oleh Pemerintah Kota Surabaya, pengembangan tersebut membutuhkan rujukan identifikasi yang nantinya dapat digunakan menjadi sarana evaluasi pelayanan agar lebih optimal.

Untuk mencapai tujuan tersebut di atas, diperlukan riset untuk mengetahui efektivitas operasional Suroboyo Bus sebagai kendaraan umum di Surabaya. Efektivitas yang dimaksud berpacu pada indikator yakni faktor muat, jumlah penumpang, waktu tunggu penumpang, kecepatan perjalanan, sebab keterlambatan, fasilitas dan ketersediaan angkutan. Sebagai studi kasus, Rute Merr-ITS dipilih menjadi materi observasi karena dianggap merupakan rute yang ramai penumpang baik pada jam sibuk maupun tidak. Metode yang digunakan adalah dengan observasi partisipan, metode ini merupakan bagian dari observasi dimana peneliti terlibat langsung dengan kegiatan dan orang yang sedang diamati atau sebagai sumber data penelitian. Sambil melakukan pengamatan, peneliti juga melakukan kegiatan yang sedang dikerjakan oleh sumber data. Hal tersebutlan yang mebuat data yang diperoleh akan lebih lengkap.

\section{METODE PENELITIAN}

Metode yang digunakan untuk mengidentifikasi permasalahan operasional rute Merr-ITS adalah observasi partisipan. Observasi partisipan, adalah metode dasar antropologi, diadaptasi untuk penggunaan desain [3]. Dalam penelitian, observasi diartikan sebagai mengamati pola perilaku orang dalam situasi tertentu untuk memperoleh informasi tentang fenomena yang menarik. Pengamatan adalah cara penting untuk mengumpulkan informasi tentang orang karena orang tidak selalu melakukan apa yang mereka katakan [4]. Observasi partisipan merupakan metode etnografi mendalam untuk memahami situasi dan perilaku melalui pengalaman partisipasi keanggotaan dalam suatu kegiatan, konteks, budaya, atau subkultur [5]. Pengamatan dan pencatatan yang sistematis sangat penting, mendokumentasikan tidak hanya apa yang terbukti secara fisik di lingkungan, tetapi perilaku, interaksi, bahasa, motivasi, dan persepsi peserta [6]. Untuk tujuan ini, pengamatan peserta umumnya dikombinasikan dengan beberapa metode lain, termasuk wawancara. John Zeisel membahas pengamatan dari sudut pandang pengamat, mengidentifikasi dua tingkat Partisipasi [7]. Partisipan marjinal (Marginal participants) berbaur dengan lingkungan sebagai pengamat alami dari suatu kegiatan atau acara. Misalnya, peneliti dapat naik bus untuk menonton komuter transit, atau menghadiri sepak bola untuk mengamati perilaku audiens sedangkan partisipan penuh (full participants) menjadi anggota kelompok, subkultur, atau budaya yang lengkap, dalam kasus-kasus ekstrem melalui infiltrasi atau peran terselubung.

Pengamatan partisipan bukan metode tunggal tetapi gaya penelitian yang khas yang memanfaatkan sejumlah metode dan teknik observasi, wawancara informan, analisis dokumen, wawancara responden, dan partisipasi dengan analisis diri [8]. Berdasarkan penjelasan diatas, selain observasi partisipan, metode pendukung yang digunakan adalah wawancara dan analisis dokumen dimana analisis dokumen merupakan sebuat pendokumentasian pada saat proses observasi. Yang dimaksud dengan wawancara adalah percakapan dengan maksud tertentu. Percakapan itu dilakukan oleh dua pihak, yaitu pewawancara (interviewer) yang mengajukan pertanyaan dan yang diwawancarai yang memberikan jawaban atas pertanyaan [9]. Dokumentasi dari asal katanya dokumen, yang artinya barang-barang tertulis. Didalam melaksanakan metode dokumentasi, peneliti mencari data mengenai hal-hal atau variabel yang berupa catatan, trnaskrip, buku, surat kabar, majalah, agenda, foto, dan sebagainya [10].

Dalam permasalahan Suroboyo Bus pengamat bertindak sebagai partisipan marjinal dan partisipan penuh yang berpartisipasi dalam aktivitas di tempat penelitian. Hasil dan tujuan yang dicapai dalam penelitian ini adalah untuk membentuk koneksi, empati, dan mengetahui kebiasaan serta interaksi, motivasi, dan persepsi terhadap pengguna Suroboyo Bus pada Rute Merr-ITS. Berikut merupakan proses dari metode yang telah dilaksanakan.

\section{Observasi Pertama}

Peneliti sebagai partisipan marginal, melakukan pengamatan pada tanggal 19 Oktober 2019 di Halte ITS, untuk memperoleh informasi mengenai kepadatan penumpang Suroboyo Bus berdasarkan faktor muat dan jumlah penumpang, ketersediaan angkutan, waktu tunggu serta ketepatan jadwal.

\section{Observasi Kedua}

Observasi dilakukan dilokasi yang berbeda pada tanggal 20 Oktober 2019, yaitu di tempat penukaran tiket Arif Rahman Hakim yang digunakan untuk penukaran botol plastik dengan tiket Suroboyo Bus. Observasi ini bertujuan untuk melakukan pengamatan terhadap tempat penukaran tiket dan jumlah bus yang beroperasi. 


\section{3.bservasi Ketiga}

Setelah itu observasi tahap ketiga dilakukan dengan observer sebagai partisipan marjinal di tempat penukaran tiket Arif Rahman Hakim pada tanggal 22 Oktober 2019. Observer menjadi calon pembeli tiket untuk mengetahui dan merasakan secara langsung mengenai tata cara naik Suroboyo Bus. Selain itu, observer melakukan pencarian informasi kepada petugas Suroboyo Bus untuk mendapatkan data sekunder dengan cara wawancara langsung.

\section{Observasi Keempat}

Observarsi tahap keempat observer mengobservasi 3 tempat, yaitu Halte ITS, suroboyo Bus dan Halte Koni. Observer menjadi seorang penumpang Suroboyo Bus untuk mengamati ketepatan waktu kecepatan perjalanan, sebab keterlambatan, fasilitas, dan rute jalan Suroboyo Bus.

\section{HASIL DAN PEMBAHASAN}

Berdasarkan hasil observasi hari pertama pada tanggal 19 Oktober 2019 yang dilakukan di lokasi Halte ITS dengan rute UNESA-ITS, peneliti berperan sebagai Marginal Participant. Secara keseluruhan terlihat bahwa jumlah penumpang sedikit pada siang hari seperti yang ditunjukkan pada Gambar 2, dan bertambah pada saat sore dan pagi hari dikarenakan jam-jam sibuk.
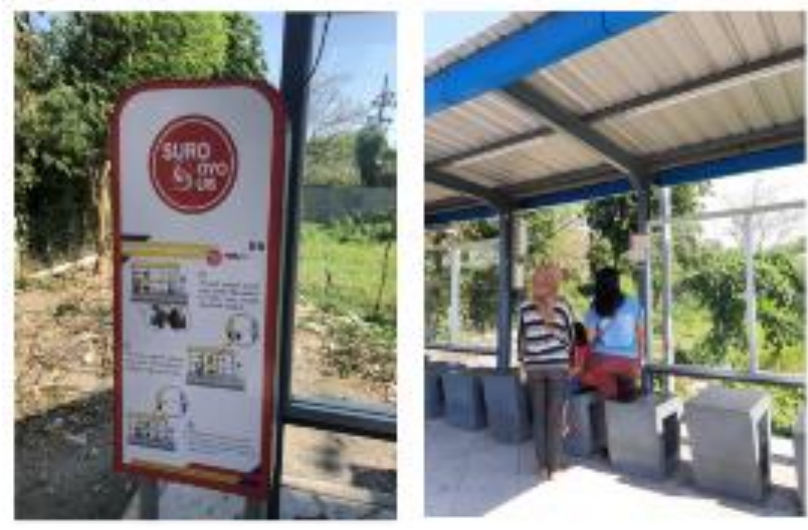

Gambar 2. Suasana di Halte UNESA pada siang hari.

Beberapa kedatangan bus tidak sesuai dengan jadwal yang telah ditetapkan, bahkan terdapat bus yang datang di waktu yang bersamaan sehingga penumpang yang berada di halte menunggu cukup lama. Jadwal bus selain tertera di halte, dapat diakses melalui aplikasi GoBis yang menyediakan beberapa fitur. Salah satu fitur aplikasi tersebut adalah bus tracker, namun yang perlu menjadi catatan, nomor bus yang tertera di aplikasi tidak sesuai dengan nomor bus yang beroperasi pada saat itu. Jadi penumpang tetap diminta untuk memperhatikan nomor bus sesuai dengan rute yang dituju. Pada saat di bus, terlihat bahwa petugas yang berdinas sebagai kernet memiliki kualitas pelayanan yang tergolong cukup baik. Petugas selalu menanyakan kepada calon penumpang mengenai tujuan mereka sehingga meminimalisir kekeliruan menaiki bus seperti yang dapat dilihat pada Gambar 3 .

Pada hari kedua di tanggal 20 Oktober 2019, observasi yang dilakukan meliputi penukaran tiket. Terdapat beberapa titik yang melayani penukaran tiket Suroboyo Bus diantaranya adalah di jalan Arif Rahman Hakim, Terminal Purabaya dan Rajawali. Observasi hari kedua dilakukan di jalan Arif Rahman Hakim. Dalam waktu 30 menit, terdapat 3 orang yang datang untuk menukarkan botol dengan tiket Bus Suroboyo. Kemudian 30 menit berikutnya terdapat 5 orang pengunjung lagi. Rata-rata, pengunjung datang dengan membawa satu kantung plastik berukuran sedang berisikan botol plastik atau setara dengan 20 buah botol plastik berukuran sedang atau botol kemasan ukuran $600 \mathrm{ml}$. Pengunjung melakukan penukaran tiket untuk menaiki bus di kemudian hari dengan alasan supaya tidak perlu membawa botol ke halte bus. Selain menjadi tempat penukaran tiket, Arif Rahman Hakim merupakan salah satu titik pemberhentian bus dengan rute MERR. Di pemberhentian ini, bagian dalam bus dibersihkan dan botol yang terkumpul dari penumpang dipindahkan dari bus ke pos penukaran tiket seperti yang terlihat pada Gambar 4 .

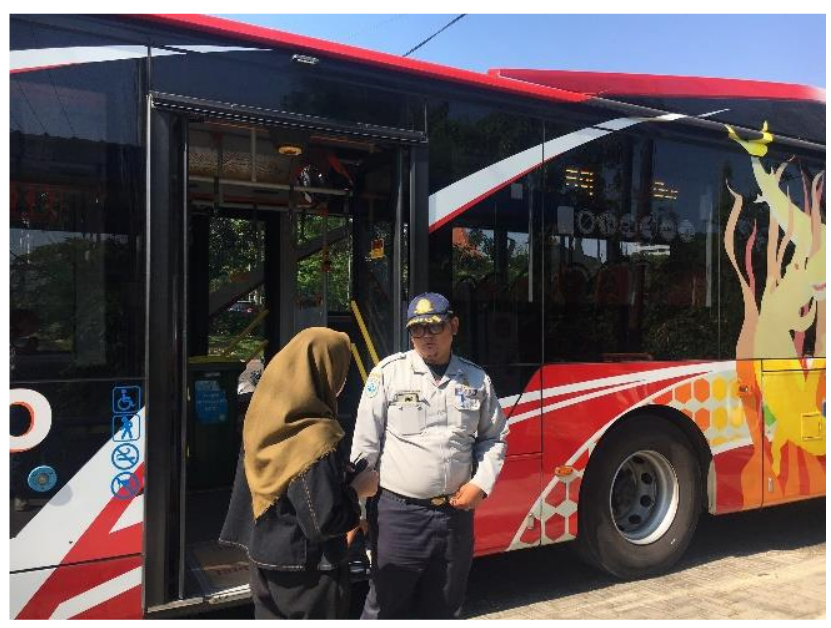

Gambar 3. Petugas memberi informasi kepada calon penumpang

Selanjutnya, observasi tahap ketiga dilakukan di tempat penukaran tiket Arif Rahman Hakim pada tanggal 22 Oktober 2019. Petugas yang berdinas pada hari tersebut adalah Bapak Trisandy Wicaksono (Gambar 5 kiri). Beliau melayani pengunjung dengan cukup baik dan menyediakan informasi yang lengkap mengenai tata cara penukaran tiket maupun informasi seputar Suroboyo Bus seperti dapat dilihat pada Gambar 5 (kanan).
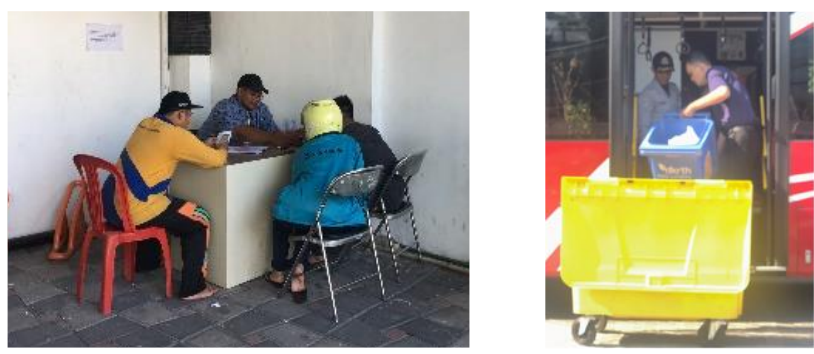

Gambar 4. Pos penukaran tiket Suroboyo Bus di Arif Rahman Hakim.

Disamping itu, tim peneliti juga mendapatkan informasi mengenai operasional Bus Suroboyo sebagai kendaraan umum untuk mengangkut penumpang dalam kegiatan sehari-hari. Halte dan rute yang juga paling dipadati oleh 
Putri Dwitasari, Nurina Orta Darmawati, Naufan Noordyanto, Vonny Aulia Sittasya, Weldiyanti Zulraniyah, Fathinah Dinda Raihanah, dan Aprilia Annisa Karim

Penggunaan Metode Observasi Partisipan untuk Mengidentifikasi Permasalahan Operasional Suroboyo Bus Rute Merr-ITS

penumpang adalah Purabaya-Rajawali dimana penumpangnya memanfaatkan Suroboyo Bus ini sebagai sarana transportasi untuk berangkat dan pulang kerja, sehingga jadwal kedatangan bus selalu tepat waktu. Sedangkan rute UNESA-ITS seringkali digunakan masyarakat untuk kegiatan rekreasional, namun tetap ada beberapa yang menggunakannya untuk transportasi seharihari. Hal ini merupakan salah satu alasan mengapa di rute ini jadwal dan nomor yang tertera di aplikasi tidak sesuai dengan bus yang beroperasi saat itu. Informasi lain yang didapatkan dari petugas adalah mengenai rencana pemerintah dalam mengupgrade tiket bus yang saat ini bermaterial karton menjadi $e$-card. Selain itu petugas juga menghimbau mengenai pemalsuan tiket bus sehingga diberlakukan peraturan dimana 1 (satu) KTP maksimal dapat dipertukarkan dengan 10 (sepuluh) tiket bus.
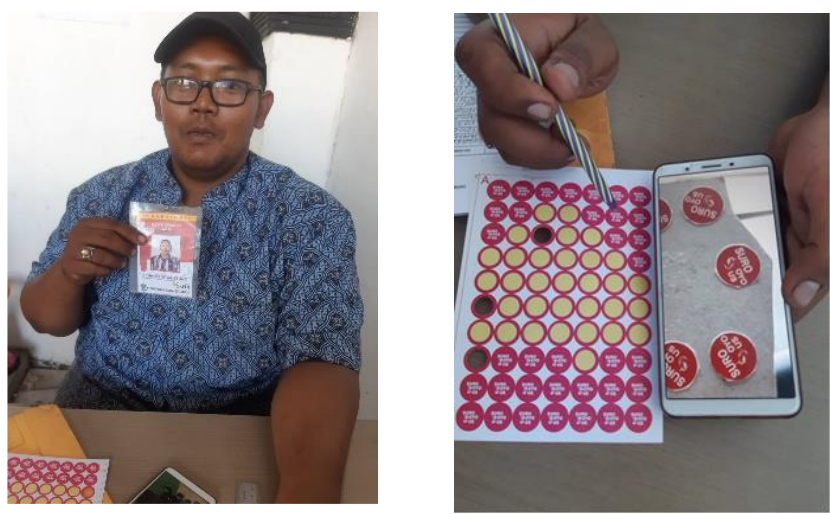

Gambar 5. Petugas di pos penukaran tiket: Bapak Trisandy Wicaksono

(kiri) dan cara Penukaran tiket, dijelaskan oleh petugas (kanan).

Observasi tahap keempat yang dilakukan pada tanggal 23 Oktober dilaksanakan di 3 (tiga) tempat sekaligus, yaitu Halte ITS, Suroboyo Bus, dan Halte Koni dimana observer sebagai partisipan menjadi penumpang Suroboyo Bus. Dari pengamatan yang dilakukan, kedatangan bus dengan nomor SB-12 tidak datang tepat waktu dengan keterlambatan sekitar 30 menit. Di dalam bus, terdapat 2 petugas yang memilik perannya masing-masing yaitu sebagai sopir dan kernet. Seperti observasi yang dilakukan di hari pertama, kualitas pelayanan petugas sangat baik dalam membantu penumpang dalam menaiki bus. Petugas Suroboyo Bus mampu memberikan pelayanan yang baik seperti langsung menanyakan kebutuhan informasi penumpang dan berusaha membantunya, contohnya dengan menanyakan tujuan penumpang serta memberi informasi mengenai rute agar tidak salah menaiki bus. Fasilitas yang disediakan di dalam bus antara lain, 5 CCTV yang tersebar di dalam area bus untuk menjamin keamanan penumpang, tempat duduk khusus wanita, interior yang ber-AC, serta tempat dan ramp untuk disabilitas seperti yang ditunjukkan pada Gambar 6 . Namun yang perlu menjadi catatan, fasilitas disabilitas terhalangi oleh tong dari penumpang seperti dapt dilihat pada Gambar 7. Selain fasilitas-fasilitas tersebut, pemberitahuan dalam bus menggunakan 3 (tiga) bahasa yaitu Bahasa Indonesia, Bahasa Jawa dan Bahasa Inggris sehingga memudahkan penumpang dalam memahami informasi yang diumumkan.

Jurusan bus yang dinaiki pada saat itu adalah MERR, namun rute yang dilewati bus sebagian tidak sesuai dengan informasi yang tertera di aplikasi GoBis bahkan ada halte yang tidak dilewati. Hal ini mengurangi keefektifan operasional bus sebagai kendaraan umum dan dapat mengganggu penumpang apabila Suroboyo Bus ini digunakan untuk sarana transportasi sehari-hari. Di haltehalte yang kecil seperti Koni, tidak disediakan tempat menunggu yang nyaman, jadwal bus tidak tertempel pada palang, namun terdapat barcode yang apabila dipindai melalui aplikasi dapat memunculkan jadwal dan posisi bus. Laju bus rata-rata di bawah batas kecepatan pada umunya yaitu $40 \mathrm{~km} / \mathrm{jam}$, sehingga penumpang yang terbiasa menggunakan kendaraan pribadi harus menyesuaikan durasi perjalanan bus yang lebih lama.
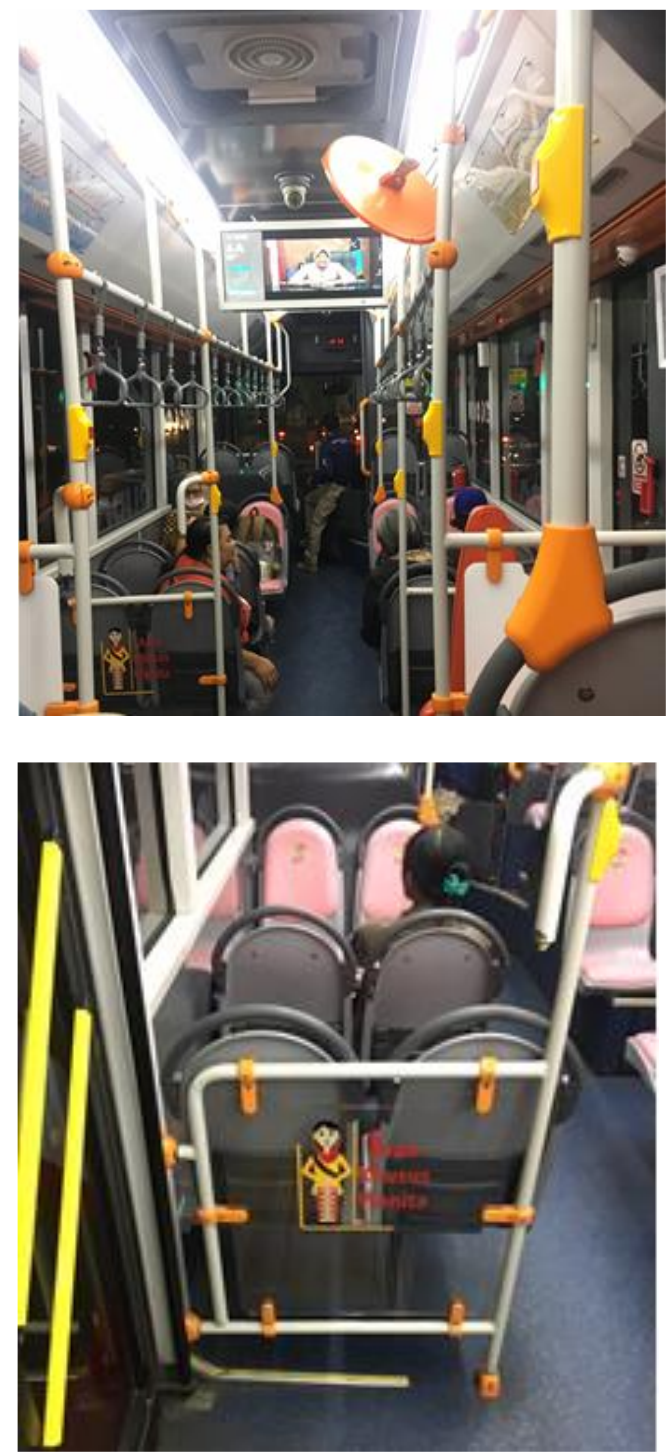

Gambar 6. Fasilitas yang tersedia di dalam Suroboyo Bus

\section{KESIMPULAN}

Berdasarkan hasil observasi, efektivitas operasional pada Suroboyo Bus rute Merr-ITS terdapat beberapa permasalahan seperti kedatangan bus tidak sesuai dengan jam yang ditentukan, nomor bus yang beroperasi tidak sesuai dengan nomor bus yang ada pada aplikasi GoBis, padahal aplikasi ini dibuat sebagai sarana pemanfaatan teknologi informasi yang berguna untuk memberikan kemudahan bagi penumpang Suroboyo bus. tidak semua halte difasilitasi dengan tempat duduk yang nyaman, serta 
terdapat halte yang tidak dilewati oleh bus, namun kualitas pelayanan serta fasilitas yang terdapat di Suroboyo bus cukup baik. Sebagai sarana moda transportasi umum modern, dalam pelaksanaan Suroboyo bus sudah berjalan dengan baik walaupun masih terdapat permasalahan.

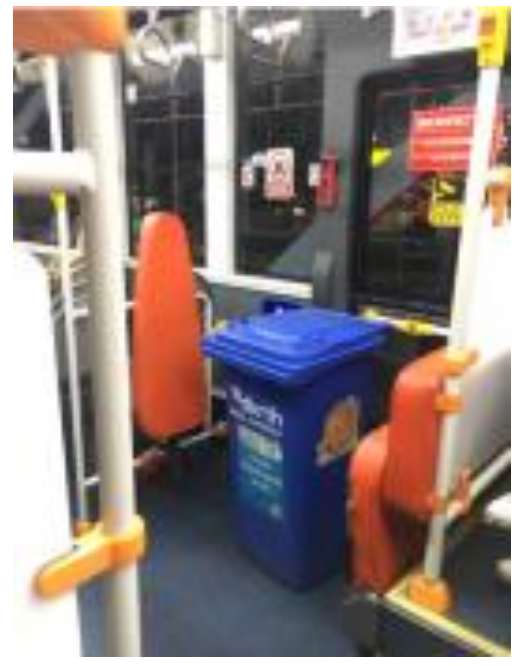

Gambar 7. Tong sampah yang menghalangi fasilitas penumpang disabilitas

Dengan hasil yang didapat dari penelitian tentang identifikasi permasalahan operasional pada Suroboyo Bus, diharapkan dapat menjadi rujukan bagi Pemerintah Kota Surabaya untuk mengevaluasi pelayanan agar lebih optimal, sehingga dapat meningkatkan efektivitas Suroboyo Bus sebagai Transportasi Umum pilihan serta andalan Kota Surabaya yang dapat dimanfaatkan oleh masyarakat Surabaya.

\section{DAFTAR PUSTAKA}

[1] Juli Hantoro, "Wali Kota Surabaya Tri Rismaharini Luncurkan Suroboyo Bus" <https://nasional.tempo.co/read/1077209/wali kotasurabaya-tri-rismaharini-luncurkan-suroboyo-bus> accesed on 2007-2020

[2] Agustina Melani, "Pemkot Surabaya Bakal Tambah 8 Unit Suroboyo Bus

2020" $<$ https://surabaya.liputan6.com/read/4118094/pemkotsurabaya-bakal-tambah-8-unit-suroboyo-bus-pada-2020\#> accesed on 20-07-2020

[3] Dewalt, K. and B. Dewalt. Participant Observation: A Guide for fieldworkers. Walnut Creek, CA: AltaMira Press, 2002

[4] Cristensen, Larry B., Research Methods, Design, and Analysis, Boston: Pearson, 2011

[5] Martin, B. d., "Universal Methods of Design", US: Rockport Publisher, (2012)

[6] Evenson, Shelley. "Directed Storytelling: Interpreting Experience for Design" in design Studies: Theory and Research in Graphic design, A Reader. New York: Princeton Architectural Press, 2006: 231-240

[7] Zeisel, John. Inquiry by design: Environment/Behavior/neuroscience in Architecture, Interiors, landscape, and Planning. New York: Norton, 2006

[8] McCall, G. J. and Simmons, J. L. (eds.) (1969) Issues in Participant Observation, Reading, Mass.: Addison Wesley, 359 pages

[9] Lexy J. Moleong, Metodologi Penelitian Kualitatif, (Bandung: PT. Remaja Rosda Karya, 2002), hal. 135

[10] Lexy J. Moleong, Metodologi Penelitian Kualitatif, (Bandung: PT. Remaja Rosda Karya, 2002), hal. 206 